\title{
The architecture of the middle ear in the small Indian mongoose (Herpestes Javanicus)
}

\author{
Y. Kamali ${ }^{1}$, S. Gholami ${ }^{1}$, M.S. Ahrari-Khafi ${ }^{2}$, B. Rasoulii ${ }^{1}$, H. Shayegh ${ }^{3}$ \\ ${ }^{1}$ Department of Anatomy and Embryology, School of Veterinary Medicine, Shiraz University, Shiraz, Iran \\ ${ }^{2}$ Department of Clinical Sciences, School of Veterinary Medicine, Shiraz University, Shiraz, Iran \\ ${ }^{3}$ Veterinary Undergraduate Student, School of Veterinary Medicine, Shiraz University, Shiraz, Iran \\ [Received 5 February 2015; Accepted 15 April 2015]
}

\begin{abstract}
The small Indian mongoose (Herpestes javanicus) is native to the Middle East, Iran and much of southern Asia. For this study the middle ears of a total of 6 adult small Indian mongooses, both fresh and museum samples were explored by using of dissection and plain radiography. On the one hand, at least in some species of the mongoose vocalisations and hearings play a critical role in coordinating behaviours. On the other hand, the ear region has provided useful character relevant for mammalian phylogeny. So, the aim of the present study is a brief discussion of the various anatomic particularities of the middle ear based on a combination of existing data and the results of the authors' study in the small Indian mongoose. (Folia Morphol 2015; 73, 3: 340-345)
\end{abstract}

Key words: anatomic description, auditory ossicles, chorda tympani, middle ear, small Indian mongoose

\section{INTRODUCTION}

The middle ear in mammals is an ear filled space in a part of the temporal bone [6]. The structure of the middle ear in domestic animals and several laboratory species has been described in detail $[2,4$, $12,21]$. However, in regards to the wildlife is poorly understood. Obviously, knowledge of the comparative morphology of mammalian middle ear structures may lead to new advances in the medical auditory researches.

Mongooses are some of the smallest carnivores that occupy a wide range of habitats, from deserts to tropical forests, across their natural range in Africa and Asia. Among them, the small Indian mongoose (Herpestes javanicus) is native to the Middle East, Iran and much of southern Asia [3]. At least in some species of the mongoose vocalisations and hearings play a critical role in coordinating behaviours [17]. Hence, for the evaluation of these properties a detailed description of the middle ear constructive apparatus is prerequisite. In the literature, no comprehensive publication regarding morphological description of the middle ear in the small Indian mongoose is available and in most publications only briefly hints exist. So, the aim of the present study is a brief discussion of the various anatomic particularities of the middle ear in the small Indian mongoose.

\section{MATERIALS AND METHODS}

For this study the middle ears of a total of 6 adult small Indian mongooses, both fresh and museum samples were explored. The 2 fresh specimens in terminal stages of disease and near death (severe hypothermia; $36^{\circ} \mathrm{C}$ body temperature) were admitted from the Park Zoo in Shiraz to our centre (Department of Anatomy and Embryology, Shiraz University, Iran). 
Table 1. Dimensions of the small Indian mongoose auditory ossicles. Data are presented as mean \pm standard deviation (SD)

\begin{tabular}{lcc}
\hline Ossicles & Parameters & Mean \pm SD \\
\hline Malleus & Total length & $5.20 \pm 0.15$ \\
& Head length & $1.36 \pm 0.15$ \\
& Head width & $1.25 \pm 0.04$ \\
& Neck length & $0.55 \pm 0.11$ \\
& Manubrium length & $3.42 \pm 0.32$ \\
\hline Incus & Total length & $1.87 \pm 0.13$ \\
& Body length & $1.08 \pm 0.13$ \\
& Body width & $1.45 \pm 0.04$ \\
& Long crus length & $1.26 \pm 0.11$ \\
& Short crus length & $0.85 \pm 0.01$ \\
\hline Stapes & Total height & $1.4 \pm 0.06$ \\
& Head width & $0.41 \pm 0.11$ \\
& Footplate width & $0.92 \pm 0.08$ \\
\hline
\end{tabular}

The animals for relief were euthanased with Ketamine $10 \%$ and Xylazine $2 \%$ and the heads of them fixed in $10 \%$ phosphate buffered formaldehyde for at least 10 days. The other 4 samples were also provided from the Shiraz Museum of Natural History, Iran. All specimens were dissected under a binuclear stereomicroscope (Carl Zeiss, Made in Germany) and the bony tympanic bullae carefully opened. Radiography was performed using a conventional $\mathrm{X}$-ray machine (Philips), with the following details: $10 \mathrm{mAs}, 45 \mathrm{kV}$, $100 \mathrm{~cm}$ focus film distance. The auditory ossicles after detailed dissection were removed and measured with an ocular micrometre, as well as the means and standard deviations of measurements were recorded (Table 1).

\section{RESULTS}

The anatomic description which follows is based on a combination of existing data and the results of the authors' study.

Two sections of the tympanic membrane (TM) were routinely determined, the smaller dorsal pars flaccida forming the upper quadrant of the TM and the larger pars tensa. In the small Indian mongoose, the pars flaccida resemble the cat and most dogs was flat (Fig. 1). The central area of the pars tensa was attached to the lateral surface of the manubrium of the malleus and the periphery was anchored to the medial wall of the external acoustic meatus.

During dissection, rupture of the TM in all specimens occurred radially and the central portion was

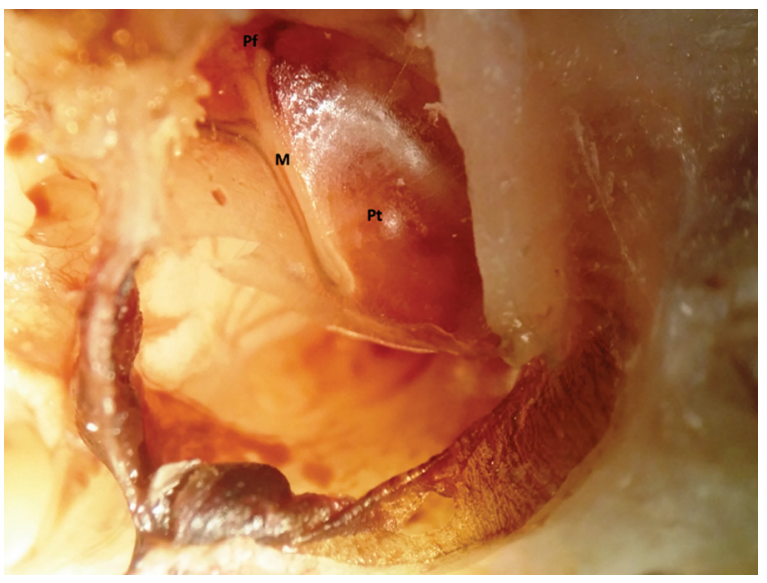

Figure 1. The tympanic membrane as viewed from the right ear canal. Notice the manubrium (M) of the malleus, the stria mallearis that seems straight. Also, the pars flaccida (Pf) is flat and pars tensa $(\mathrm{Pt})$ has been ruptured peripherally.

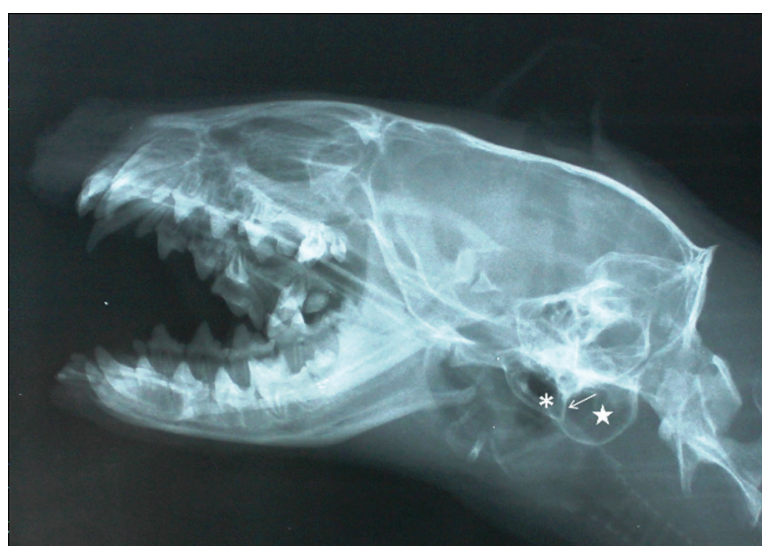

Figure 2. Plain radiography of the head in slightly lateral oblique view. The star $(\star)$ shows the bullar cavity and the asterisk (*) depicts the tympanic cavity. The white arrow shows the septum bulla.

firmly stuck to the manubrium and hardly isolated (Fig. 1). When viewing the external aspect of the TM due to semitransparency of its appearance, the handle of the malleus, the stria mallearis, seemed straight with no hook shape (Fig. 1).

As described for all other felids, the middle ear space partitions by a complete bony septum into two separate compartments: the dorsolateral tympanic cavity and the ventromedial bullar cavity. The larger compartment, i.e., bullar cavity is lying ventral, medial and caudal to the smaller one. The connection between the two regions is possible only through a narrow foramen between the septum and the petrous bone (Figs. 2, 3). The promontory of the petrous bone embedding the cochlea is located on the medial wall 


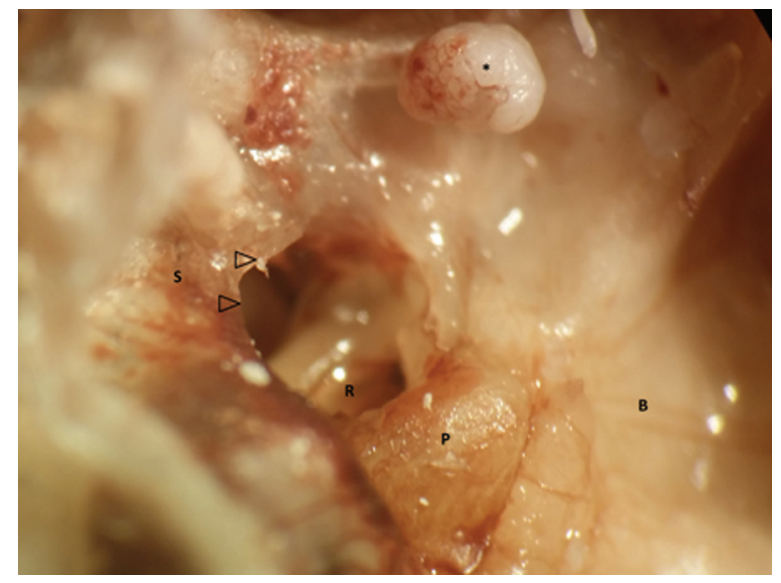

Figure 3. Caudodorsal aspect of the right bulla. The bulla has been opened and the margin of the complete septum (S) is arrowed. Notice the part of promontory $(\mathrm{P})$ that is seen through the connecting foramen from the bullar cavity (B). The asterisk $\left({ }^{*}\right)$ depicts a bony cresset is hanging from the dorsolateral aspect of the bullar cavity; R - round window.

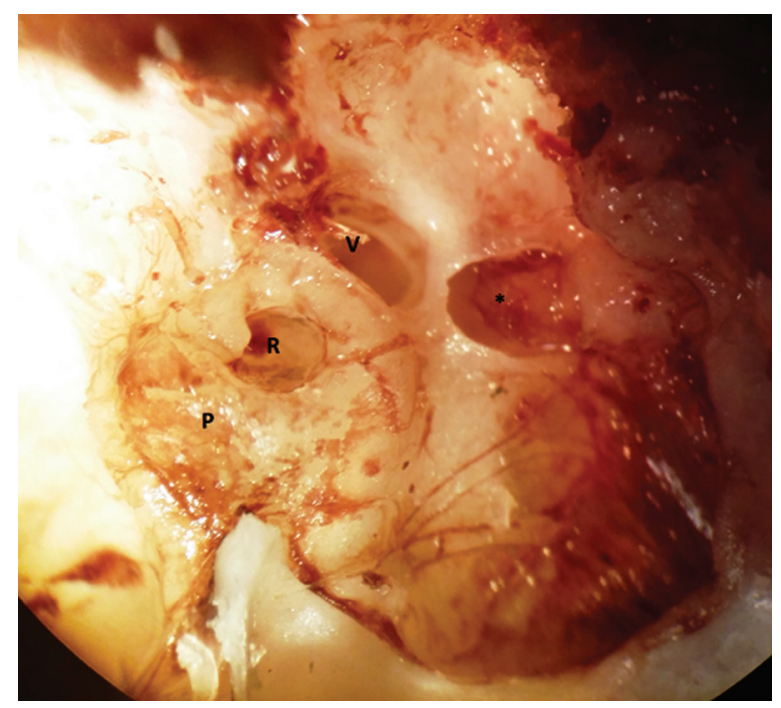

Figure 4. Lateral aspect of the right tympanic cavity showing promontory $(\mathrm{P}) ; \mathrm{R}$ - round window; $\mathrm{V}$ - oval window; asterisk $\left({ }^{*}\right)$ bonny tunnel for tensor tympani muscle.

of the tympanic cavity, medial to the epitympanic recess. Some bony cressets are also hanging from the dorsolateral aspect of the bullar cavity. Two foramens, i.e., the cochlear (round) window and vestibular (oval) window are located on the caudolateral portion and on the dorsolateral surface of the promontory, respectively. The opening of a bony tunnel is rostral and slightly ventral to the oval window from which the tensor tympani muscle projects to the tympanic cavity and inserts on a muscular process of the ma-

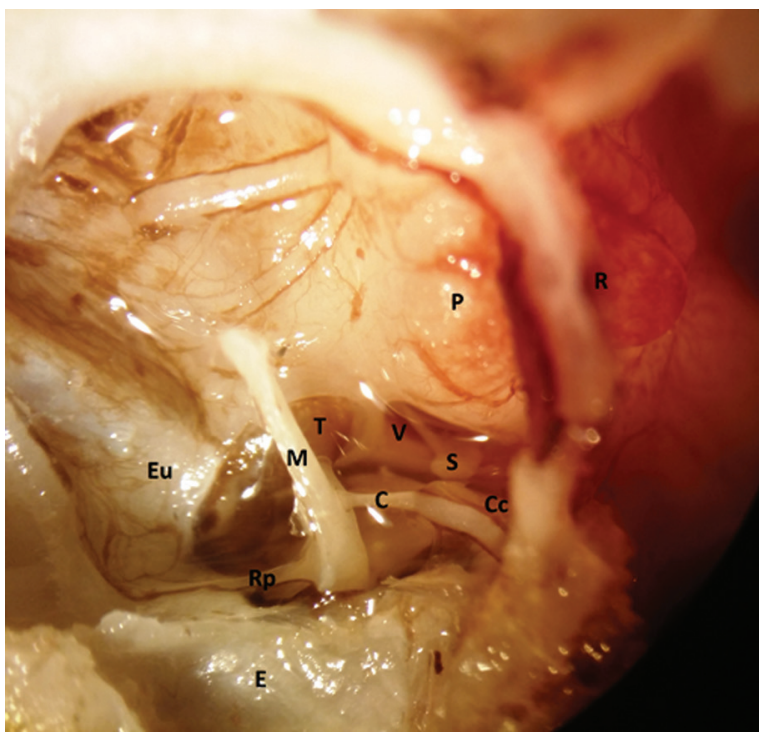

Figure 5. Ventrolateral view of the right tympanic cavity depicting; $\mathrm{E}$ - ear canal; $\mathrm{Eu}$ - Eustachian tube; $\mathrm{M}$ - manubrium; $\mathrm{Rp}-$ rostral process; $\mathrm{C}$ - chorda tympani; $\mathrm{Cc}$ - conical cartilage; $\mathrm{T}$ - tensor tympani; $\mathrm{P}$ - promontory; $\mathrm{R}$ - round window; $\mathrm{V}$ - oval window; $\mathrm{S}$ - stapes.

nubrium (Fig. 4). The other ostium is related to the caudal extremity of the auditory tube that is at the rostral portion of the tympanic cavity (Fig. 5).

In the small Indian mongoose such as all mammals there are 3 ossicles of the middle ear, named respectively the malleous, incus, and stapes. The malleus is the largest bone of the auditory ossicles with the average length $2.85 \mathrm{~mm}$. It is attached to the TM via the stria mallearis, the ectotympanic via the spine (the distal tip) of the tympanic plate of the rostral process, and the incus by the head. In contrast to the well-developed head, the osseous lamina is very delicate and can break during removal of the ossicle (Fig. 6). From the anteroventral termination of the osseous lamina a thickened ventral margin projects as the rostral process; also, the tympanic plate as a pendent from the latter process is flattened onto the overlying squamosal and mediolaterally expanded. The muscular process does not arise from the neck close to the base of the manubrium as in the other carnivores, but from the inner edge of the manubrium itself (Fig. 7). The most dorsal attachment of the manubrium to the TM, opposite the muscular process, at a right angle with the rostral process is the lateral process. One of the outstanding features in the malleus is existence of a transverse bonny channel slightly above the root of the muscular process 


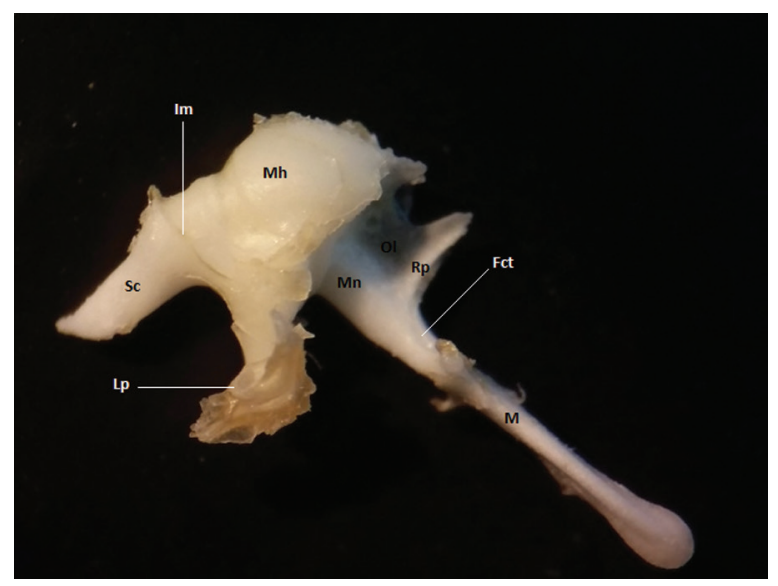

Figure 6. The malleus and incus of the right ear in medial view. The malleus and incus are articulated to form the incudomallearis joint (Im); $\mathrm{M}$ - manubrium; $\mathrm{Mh}$ - mallear head; $\mathrm{Mn}$ - mallear neck; Ol — osseous lamina; Rp — rostral process; Fct — foramen for chorda tympani; $\mathrm{Lp}$ - lenticular process or bone; $\mathrm{Sc}$ - short crus of the incus.

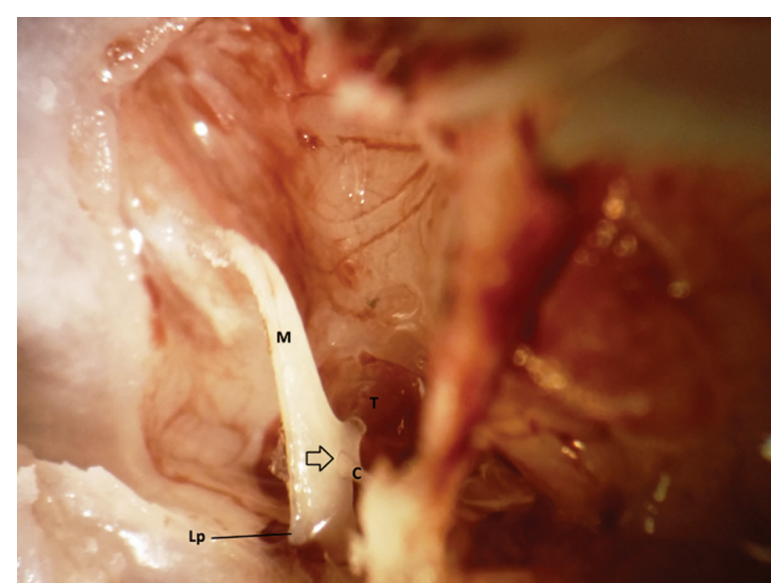

Figure 7. Ventrolateral view of the right tympanic cavity with higher magnification. The arrowhead shows the foramen for chorda tympani through which the chorda tympani (C) traverses; Lp lateral process; $\mathrm{M}$ - manubrium; $\mathrm{T}$ — tensor tympani muscle.

through which the chorda tympani traverses. The bonny mallear channel (foramen for chorda tympani) was observed in all specimens (Fig. 6). The dorsal part of the manubrium is triangular in cross section, but ventrally the medial side gradually disappears. As already mentioned, the malleus handle is much more straightened and form with the neck an obtuse angle. The centre of the manubrium is not also solid and has a channel throughout its entire length. The incus displays 2 crura: the short crus is attached by a ligament to a fossa (fossa incudis) on the posterior wall of the mastoid part of the bulla, while the long crus by its lenticular process articulates with the stapedial head to form a true synovial joint. Our findings at least based on macroscopic observation show that the lenticular process is a distinct and separate ossicle (Fig. 6). Hence, it can be named lenticular bone. The incus measuring about $1.87 \mathrm{~mm}$ long by $1.45 \mathrm{~mm}$ high is suspended between the malleus and the stapes. The stapes has a head, a neck, 2 crura and a footplate. The mean stapes height is $1.4 \mathrm{~mm}$. The stapes footplate is attached to the cartilaginous rim of the oval window by an annular ligament. In most specimens, due to the firmness of this articulation, the footplate remained in the oval window and was difficult to segregate. The inner sides of the crura are vacated and the rostral crus is slightly longer than the caudal one.

The chorda tympani after branching from the facial nerve, passes medially and rostrally ventral to the conical cartilage. Afterward it runs through a bony mallear channel (foramen for chorda tympani), immediately above the muscular process of the malleus. Thereupon, the chorda tympani nerve in the small Indian mongoose has an epitenseric pattern (Fig. 7). Should be noted the conical cartilage is a structure that compressed dorsoventrally with its base situated on the dorsocaudal portion of the tympanic bone close to the TM and its apex extended toward the muscular process of the malleus.

\section{DISCUSSION}

In Felidae, Herpestidae and Viverridae a bony septum runs more or less at right angles to the lower wall of the auditory bulla and dividing it into 2 cavities that are coupled through a small opening [26]. One has therefore merely to cut through the lower wall in order to see the septum or, indeed, it can usually be seen through the external acoustic meatus or felt by inserting a probe. In the domestic dog, the bulla septum is a small, incomplete ridge that only makes contact with the petrous portion of the temporal bone rostrally and often has tiny, elongate bony spicules with bulbous ends $[7,18]$. The function of the septum bulla has not been investigated in carnivores.

Despite our increasing understanding of the tympanic plate of the mallear rostral process in carnivores, many comparative anatomical textbooks still describe a short rostral process which is not coupled to the 


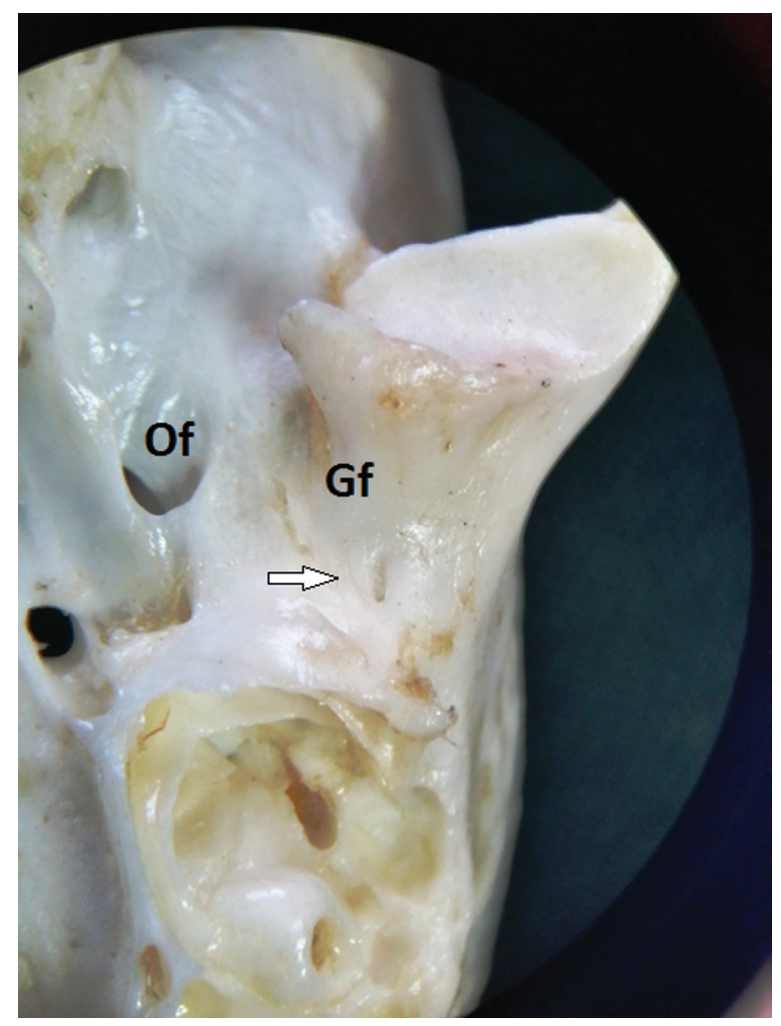

Figure 8. Left basicranium in ventral view depicting the fused spine of the tympanic plate of the mallear rostral process (arrow); Of — oval foramen; $\mathrm{Gf}$ — glenoid fossa.

ectotympanic [10, 22]. Wible and Spaulding [23] presented a comparative morphological study on the malleus of 15 stock families of carnivores. They suggested that a long tympanic plate of the rostral process is anchored to the ectotympanic in a disparate classification of juvenile and adult carnivores, and, with aging, the fate of the tympanic plate is sutural fusion to the auditory bulla (Fig. 6). According to opinion of Henson [13] the rostral process has composed of 3 principal parts: the osseous lamina, the pars processus anterioris, and the tympanic plate. In our samples due to aging the tympanic plate was fused to the auditory bulla and the spine of the tympanic plate is set off by sutures from the ectotympanic on the anterior face of the bulla (Fig. 8).

As the lenticular process is a superfine and has a weak bond with the long crus of incus, some authors therefore consider the lenticular process as a separate bone [e.g., 24, 25]. However, Eysell [8] based on a histological section showed that a continuous bony connection exists between the lenticular process and long crus of the incus. In contrast to human anatomy, sufficient evidence regarding the lenticular process of other species has not been presented. In this regard, more detailed descriptions of the lenticular process by Hyrtl [14], Doran [5], and Henson [13] have been conducted. Hyrtl [14] treated this process as a dependent ossicle and an apophysis of the lung process of the incus in all animals. Doran [5] referred to it as an apophysis, or perhaps epiphysis, of the incus, and cited the beautiful description by Eysell [8]. Henson [13] described middle ear structures in 3 insectivores and 8 bats; his overall description of the lenticular process was "a small cartilaginous disk mounted on an osseous pedicle".

The conical cartilage has been described only in domestic cats. As mentioned above, a similar structure was found in the middle ear of the 2 fresh specimens. It is known that this structure lies across the opening between the auditory bulla and middle ear proper and divides the opening into a dorsal and ventral portion. Its apex rests on the promontory ventral to the oval window and rostral to the round window niche [15]. However, in contrast to the cat, we noticed that the apex of the conical cartilage was away from the promontory and directed toward the muscular process of malleus. In the cat's middle ear, this conical structure was detected the first by Davey [4]. He suggested that its embryonic origin might be from the second arch bar (Reichert's cartilage).

In the point of view of mammalian phylogeny, the spatial relationship of the chorda tympani to the tensor tympani muscle in the middle ear of carnivores can be helpful. Regarding the course of the chorda tympani, there are two different patterns in general: a hypotensoric pattern with the nerve running below the insertion tendon of the tensor tympani muscle, and an epitensoric pattern with the nerve running above the tendon [20]. In almost all mammals the chorda tympani passes underneath the tendinous insertion of the tensor tympani muscle at the malleus $[11,16,19]$. However, in some rodents and primates, the course of the chorda tympani shows a derived condition $[9,11,16,19]$. To resolve problems of phylogenetic systematic of carnivores, some authors have investigated the middle ear of different species of carnivores only histologically $[1,16,19,20]$. In accordance with these studies, the canids, ursids, phocids, ailurids, mustelids, felids, nandiniids, euplerids, and viverrids showed the hypotensoric state. In contrast, the epitensoric condition observed in $\mathrm{M}$. mungo, S. suricatta, H. javanicus, and G. sanguine $[1,20]$. 
According to the above description, the study confirmed the epitensoric state of the chorda tympani at least in the small Indian mongoose morphologically.

\section{CONCLUSIONS}

In conclusion, the results in this study suggest that the anatomy of middle ear in the small Indian mongoose could be extended rather simply for entire family Herpestidae.

\section{ACKNOWLEDGEMENTS}

The authors are grateful to collection staff at the Shiraz Museum of Natural History for allowing access to the specimens. This research was financially supported by grants of Shiraz University Research Council.

\section{REFERENCES}

1. Bondy G (1907) Beitrage zur Vergleichenden Anatomie des Gehororgans der Saugetiere (Tympanicum, Membrana Shrap nelli und Chordaverlauf). Anat Hefte, 35: 293-408.

2. Cooper G, Schiller AL (1975) Anatomy of the guinea pig. Harvard University Press, Cambridge.

3. Corbet GB, Hill JE (1992) The Mammals of the Indomalayan region: a systematic review. Oxford Univer City Press, Oxford, UK.

4. Davey LM (1979) An atlas of microscopic dissection following the attic approach to the cat's middle ear. J Am Audit Soc, 5: 138-148.

5. Doran AHG (1878) Morphology of the mammalian ossicula auditus. 2nd series. Vol. I. Trans. Linnean Soc. London 1879: 371-3497 + plates 58-64.

6. Dyce KM, Sack WO, Wensing CJG (2010) Textbook of veterinary anatomy. 4th Ed. WB Saunders Co, Philadelphia, pp. 346-351.

7. Evans HE, De Lahunta A (2013) The ear. In: Evans HE, de Lahunta A eds. Miller's anatomy of the dog. 4th Ed. Elsevier, St. Louis, MO, pp. 731-745.

8. Eysell A (1870) Beitrage zur Anatomie des Steigbugels und Seiner Verbindungen. Arch Ohrenheilkund, 5: 237-249 +2 plates.

9. Farr MRB, Mason MJ (2008) Middle ear morphology in dormice (Rodentia: Gliridae). Mamm Biol, 73: 330-334.

10. Gaubert P, Wozencraft WC, Cordeiro-Estrela P, Veron G (2005) Mosaic of convergences and noise in morphological phylogenies: what's in a viverrid-like carnivoran? Syst Biol, 54: 865-894.
11. Gray O (1953) The chorda tympani. J Laryngol Otol, 67: 128-138.

12. Hellstrom S, Salen B, Stenfors L (1982) Anatomy of the rat middle Ear: a study under the dissection microscope. Acta Anat, 112: 346-352.

13. Henson JROW (1961) Some morphological and functional aspects of certain structures of the middle ear in bats and insectivores Univ. Kans Sci Bull, 42: 151-255.

14. Hyrtl J (1845) Vergleichend-anatomische Untersuchungen uber das innere Gehororgan des Menschen und der Saugethiere. Verlag von Friedrich Ehrlich, Prague, viii + 139 pp +9 plates.

15. Khalil MA, Spector M (1985) The conical cartilage of the cat's middle ear. J Laryngol Otol, 99; 831-838.

16. Maier W (2008) Epitensoric position of the chorda tympani in Anthropoidea: A new synapomorphic character. With remarks on the fissura Glaseri in primates. In: Sargis EJ, Dagosto M eds. Mammalian evolutionary morphology: A Tribute to Frederick S. Szalay. Springer, Dordrecht, pp. 339-352.

17. Messeri P, Masi E, Piayya R, Dessifulgheri F (1987) A study of the vocal repertoire of the banded mongoose (Mungos mungo). Ital J Zool, 22: 341-373.

18. Njaa BL (2012) The ear. In: Zachary JF, McGavin MD eds. Pathologic basis of veterinary disease. 5th Ed. Elsevier Mosby, St. Louis, MO, pp. 1153-1193.

19. Ruf I, Frahnert S, Maier W (2009) The chorda tympani and its significance for rodent phylogeny. Mamm Biol, 74: 100-113.

20. Ruf I, Maier W (2010) Topography of the chorda tympani nerve and the tensor tympani muscle in carnivores provides a new synapomorphy for Herpestidae (Carnivora, Mammalia). J Morph, 271: 612-620.

21. Vrettakos PA, Dear SP, Saunders JC (1988) Middle ear structure in the chinchilla: a quantitative study. Am J Otolaryngal, 9: 58-67.

22. Wesley-Hunt GD, Flynn JJ (2005) Phylogeny of the Carnivora: basal relationships among carnivoramorphans, and assessment of the position of 'Miacoidea' relative to Carnivora. J Syst Palaeontol, 3: 1-28.

23. Wible JR, Spaulding M (2012) A Reexamination of the Carnivora Malleus (Mammalia, Placentalia). PLoS ONE, 7: e50485.

24. Wolff D, Bellucci RJ, Eggston AA (1957) Microscopic anatomy of the temporal bone. Williams \& Wilkins, Baltimore.

25. Wolff D, Bellucci RJ, Eggston AA (1971) Surgical and microscopic anatomy of the temporal bone. Hafner, New York.

26. Wozencraft WC (1989) The phylogeny of the recent carnivora. In: Gittleman JL, Cornell UP eds. Carnivore behavior, ecology, and evolution. Ithaca, NY, pp. 495-535. 